\title{
Colleges set guidelines for marijuana
}

$\mathrm{T}$ he seven provincial colleges of physicians that have issued guidelines are urging their members to take a cautious approach to prescribing medical marijuana.

The uncertainty over the risks and benefits of the drug and the lack of reliable data on its clinical effects are underlying caveats in guidelines from the colleges. The colleges advise physicians to take great care when deciding whether to prescribe cannabis to patients and to first ensure that conventional therapies have been exhausted.

To help fill that knowledge gap, the Collège des médecines du Québec is setting up a pharmacovigilence research project with the Canadian Consortium for the Investigation of Cannabinoids, to track outcomes and adverse events.

Health Canada's new rules on medical marijuana, which came into effect on Apr.1, shift the burden of deciding whether a patient is eligible for medical marijuana from the ministry on to the physician and require patients to obtain their marijuana from official licensed suppliers.

However, the ban on patients growing their own plants has been put on hold pending a British Columbia court challenge.

The Royal College of Physicians and Surgeons of Canada says that, in light of the lack of evidence, doctors who do not feel comfortable prescribing medical marijuana should not do so. The Royal College also wants the federal government to support research on the safe use of marijuana for medical purposes. And it disagrees with having physicians write prescriptions. Instead, it says doctors should be able to sign a declaration whereby a patient meets broad criteria for accessing marijuana for medical use rather than a document akin to a prescription, to deal with issues of liability for clinicians.

Although stopping short of running research programs, the other colleges stress the need for careful record keeping. Some jurisdictions, such as Alberta,

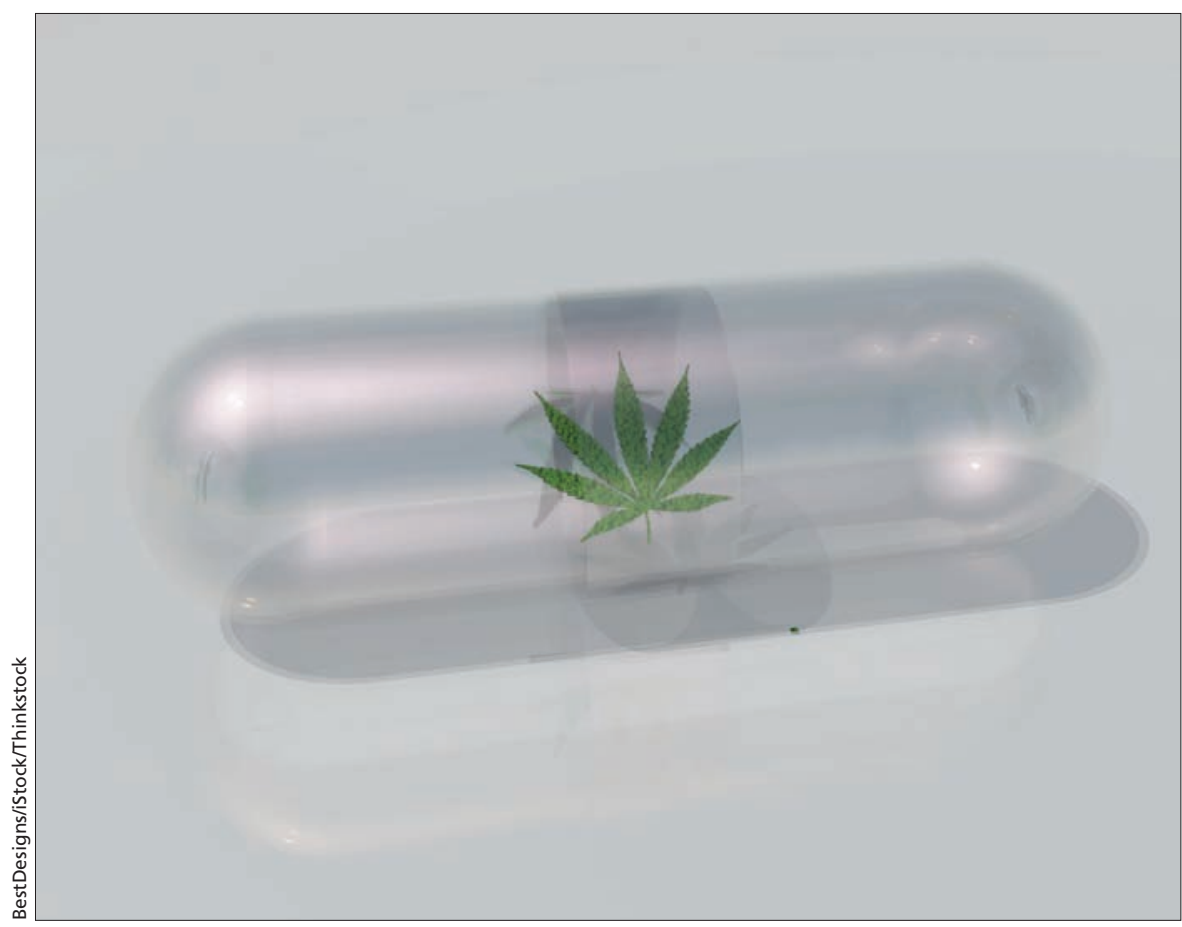

Physicians need to ensure that conventional therapies are exhausted before prescribing medical marijuana, say many provincial colleges.

require doctors to provide the college with a copy of every authorization. To stop patients from shopping around for a sympathetic doctor, many jurisdictions also require the prescribing physician to be the patient's primary doctor, or in some cases a specialist treating the patient for the specific condition that requires marijuana. Prescribing the drug via telemedicine is also discouraged; doctors are required to evaluate patients in person.

In most cases doctors are strongly discouraged or completely barred from becoming licensed producers or suppliers of marijuana, though the college in New Brunswick merely warns them to comply with the guidelines on billing for noninsured services.

Dr. Ed Schollenberg, registrar of the College of Physicians and Surgeons of New Brunswick, says that because the Health Canada regulations authorize physicians to dispense marijuana, it would be "counterproductive" to try and ban the practice. But, he says, they will have to follow strict rules that govern the dispensing of the drug: they can team up with a supplier to provide it at cost only if it is unavailable from other suppliers. If they have a financial interest in a particular grower or supplier, they must not preferentially direct patients to that business. "The key is that doctors cannot profit from prescribing," says Schollenberg.

Many of the rules may need to be tweaked as physicians get used to the new system, says Schollenberg. "It's a work in progress," he says. "We will change things if it doesn't work."

Medical marijuana advice for physicians is available for British Columbia, Alberta, Saskatchewan (Bylaw 19.2), Manitoba, Quebec, New Brunswick, and Newfoundland and Labrador. The colleges in Nova Scotia, Ontario and Prince Edward Island have not yet finalized their guidelines. - Brian Owens, St. Stephen, NB

CMAJ 2014. DOI:10.1503/cmaj.109-4803 